\title{
RESENHAS
}

\section{O INSTITUCIONAL, A ORGANIZAÇÃO E A CULTURA DA ESCOLA}

João dos Reis Silva Júnior,

Celso João Ferretti

São Paulo: Xamã, 2004, I 50p.

Qual o impacto das reformas educacionais na prática pedagógica que se desenvolve no interior das escolas, no âmbito das salas de aula? Em que grau as mudanças nas formas de trabalho, as transformações operadas nas fábricas afetam o funcionamento das escolas?

Essas questões constituem a motivação de fundo da elaboração do livro, conforme esclarecem os autores na Introdução. Após mais de dez anos de pesquisas que buscaram compreender a educação a partir do exame de dados levantados nos locais de trabalho e do estudo das reformas institucionais promovidas pelo Estado, os autores se defrontam com a "necessidade da volta à escola como lócus privilegiado de investigação" (p.19).

O livro insere-se no âmbito de um processo que se origina no início da década de 1990, com os estudos realizados no Núcleo Trabalho-Educação, do Programa de PósGraduação em Educação: História e Filosofia da Educação da PUC-SP, por um grupo de pesquisa coordenado por Celso Ferretti, ao qual se incorporou João dos Reis Silva Júnior, a partir de 1996. Esse grupo, por sua vez, se articulava com um outro grupo de pesquisa, localizado na Fundação Carlos Chagas. Os trabalhos dos dois grupos tinham como objeto o ensino médio na articulação entre os ramos secundário e técnico-profissional, buscando "apreender o impacto das transformações tecnológicas" nos ramos secundário e terciário da economia e seus "possíveis desdobramentos para a educação" (p. 16).

Paralelamente, João dos Reis participava com Valdemar Sguissardi, na Universidade Metodista de Piracicaba - Unimep -, de estudos que buscavam compreender a relação entre as mudanças na produção e as alterações que se processavam no ensino superior, como eixo para a análise das políticas públicas para a educação superior. No primeiro caso predominaram estudos centrados na Sociologia e na Economia, tendo o local de trabalho, ou seja, as empresas, como campo empírico. No segundo caso, o centro foram as propostas de reformulação do Estado e da educação, tendo como campo empírico os documentos que consubstanciavam as chamadas reformas institucionais. Em ambos os casos, o foco estava fora da escola, o que trouxe a necessidade de redirecionar o vetor das pesquisas, voltando-o para o âmbito interno da instituição escolar. É esta nova fase das investigações dos autores que se inaugura com o livro.

Assim, a obra constitui uma síntese das questões teóricas levantadas por três pesquisas, desenvolvidas com apoio da Fundação de Amparo à Pesquisa de Estado de São Paulo - Fapesp -, duas delas já concluídas: "a qualificação como relação e construção sociais: distintas leituras da obra de Marx", realizada na Pontifícia Universidade Católica de São Paulo - PUC-SP -, sob coordenação de João dos Reis Silva Júnior; "a construção social da qualificação profissional", realizada na Fundação Carlos Chagas, sob coordenação de Celso João Ferretti; e, sob responsabilidade de ambos os autores e coordenação de João dos Reis Silva Jr., "competências e prá- 
tica social: o trabalho como organizador e estruturador das reformas educacionais brasileiras no ensino médio e na educação profissional de nível técnico e sua concretização nas instituições escolares nos primeiros anos do século XXl", em andamento.

Pretendendo "fazer uma primeira produção da categoria prática escolar com base na categoria 'prática social' tomada de Lukács" e "desenvolvendo um movimento de apreensão da especificidade da instituição escolar por meio de sua natureza institucional, de sua específica organização derivada do institucional e da cultura escolar" (p.23), os autores organizaram o plano da exposição em quatro capítulos.

O primeiro capítulo, "As reformas institucionais e seu impacto nas pesquisas educacionais", apresenta brevemente as características da atual conjuntura planetária, nela situando o descompasso dos indicadores do quadro educacional brasileiro, evidenciado pelas pesquisas, quadro esse agravado pelas reformas que acentuam o contraste entre a restrição da esfera pública e a expansão da esfera privada. Diante da constatação de que "as reformas, tal como propostas no âmbito do Estado, não se realizam necessariamente de acordo com o espírito que as anima" (p.44), os autores concluem pela necessidade de investigar, diante das imposições legais, o que efetivamente está acontecendo na escola. Para essa investigação elegem como categorias centrais os conceitos: "institucional", "organização" e "cultura da escola".

O objeto do segundo capítulo, denominado "O institucional, a organização e a cultura na escola", é exatamente esclarecer o significado daquelas categorias centrais. Entendendo que a escola é um produto típico da modernidade, recorre-se a Locke, especialmente com base em sua obra Segundo tratado sobre o governo, para entender como se deu a configuração do Estado moderno do qual deriva o institucional e, daí, a instituição escolar, sua organização e sua cultura. E, para detalhar a conceituação do "institucional", da "organização" e da "cultura escolar", os autores recorrem às obras de Beltrán Llavador e San Matín Alonso, Diseñar la coherencia escolar e de Ball, La micropolítica de la escuela, advertindo, porém, que partem de uma orientação teórica distinta daquela desses autores posicionando-se, portanto, criticamente em relação a eles.

No terceiro capítulo, "Instituição e prática escolar: apropriação e objetivação", explicita-se a perspectiva teórica que se pretende seja a orientação que guia toda a análise e interpretação dos temas tratados no livro. $\bigcirc$ fundamento dessa perspectiva teórica é dado por Lukács, especificamente em seu trabalho sobre a "ontologia do ser social", apreendido por meio das publicações italianas Per una ontologia dell'essere sociale e Prolegomini all'ontologia dell'essere sociale. Os conceitos-chave aí explorados são "apropriação" e "objetivação", com base nos quais se busca compreender a categoria de "prática social". Em termos complementares recorre-se, também, à discípula de Lukács, Agnes Heller, Sociologia de la vida cotidiana, como um recurso para se abordar a prática escolar no entrecruzamento das atividades cotidianas e não-cotidianas. Nessa abordagem estabelece-se, ainda, uma interlocução com a leitura de Lukács e de Heller, feita por Newton Duarte (A individualidade para-si; Educação escolar, teoria do cotidiano e a escola de Vigotski; Vigotski e o "aprender a aprender").

No quarto capítulo, "Algumas indicações para o estudo de práticas escolares de escolas brasileiras", os autores reportam-se, de passagem, a alguns "intérpretes do Brasil" (Gilberto Freire, Sérgio Buarque de Holanda, Celso Furtado, Florestan Fernandes), para destacar "alguns elementos históricos e cul- 
turais da sociedade brasileira que permitirão entender melhor os principais traços da cultura e prática escolares no presente" (p. I I 5). Em seguida, comentam, a título de ilustração, algumas pesquisas que, por suposto, trariam elementos úteis à análise das práticas escolares características da situação educacional brasileira. As pesquisas comentadas são: a. a trilogia publicada por Luiz Antonio Cunha em 2000 ( $O$ ensino de ofícios artesanais e manufatureiros no Brasil escravocrata; O ensino de ofícios nos primórdios da industrialização; e $O$ ensino profissional na irradiação do industrialismo); b. a de João dos Reis Silva Júnior, A formação da universidade metodista de Piracicaba; c. a de Luiz Carlos Barreira, que toma como fonte o jornal O operário, do início do século $X X$; d. uma dissertação de mestrado sobre duas escolas municipais de Sorocaba. Completando a ilustração, os autores apresentam sua própria visão da trajetória da universidade de Sorocaba.

Nas Considerações finais, João dos Reis e Celso Ferretti sintetizam os principais temas tratados no livro e anunciam o propósito básico das pesquisas que pretendem desenvolver: estudar, de um lado, "as reformas educacionais e a produção do pacto social em construção na instituição escolar e, de outro, produzir, por meio da pesquisa, maior precisão e especificidade para a categoria prática escolar com base nas categorias prática social, tomada de Lukács, e cotidianidade, tomada de Heller" (p. I45).

O livro tem o inegável mérito de colocar em evidência uma questão de extrema relevância e atualidade: a necessidade de se compreender a especificidade da escola e as características próprias da prática que se desenvolve em seu interior. Louve-se, também, a iniciativa dos autores de trazer a público e submeter a debate as suas reflexões, que expressam mais a busca inquieta de caminhos para um empreendimento investiga- tivo que está se iniciando do que resultados amadurecidos do próprio processo de pesquisa. Assim, como assinalou Newton Duarte no prefácio, a publicação do livro dá "ao leitor o direito de também participar de uma prática que se vem tornando algo raro e depreciado no meio universitário: o debate acadêmico" (p.9). É no espírito do exercício desse direito que passo a comentar aspectos provocados pela leitura da obra.

Começando pelo título: "O institucional, a organização e a cultura da escola". Por que os autores foram levados a substantivar o adjetivo "institucional" em lugar de usar o próprio substantivo "instituição"? E por que isso não ocorreu com o termo "organização"? Quanto à expressão "cultura da escola", ela se converte em "cultura na escola", no título do capítulo 2, que repete a denominação do conjunto do livro. Por quê? Embora essas perguntas não incidam sobre aspectos substantivos do trabalho analisado, seu esclarecimento poderá situar melhor o leitor, facilitando-Ihe a leitura da obra. São lançadas, pois, como uma sugestão aos autores diante da possibilidade, bastante concreta, do imediato lançamento de uma nova edição.

Considerando-se o recorte adotado, que circunscreve a análise da escola à época moderna, os autores entendem a instituição escolar como um produto típico da modernidade. Esse entendimento aparece em vários momentos do texto: "a instituição escolar tem sua origem na produção histórica do Estado moderno" (p. 49); "o institucional se fez com o Estado moderno" (p.54); "não há, portanto, sentido em se falar de público e institucional na ausência do Estado moderno" (p.54); "a esfera mais reiterada na sociedade de classes na modernidade: a educação escolar" (p.98); "a instituição escolar emerge na História como necessidade da formação do ser social construtor do pacto social burguês" (p. I08); o específico da 
escola deve ser buscado na sua origem histórica na modernidade" (p. | |0).

Ainda que o recorte analítico justifique, de certo modo, o destaque conferido à forma particular assumida pela escola na vigência do modo de produção capitalista, a linguagem enfática, evidenciada nas transcrições apresentadas, pode conduzir os leitores à conclusão de que a institucionalização da educação só teria ocorrido na época moderna.

Para evitar essa leitura, a meu ver equivocada, penso ser desejável proceder à distinção entre a gênese histórica da instituição escolar e a emergência da escola como forma principal e dominante de educação. A institucionalização da educação e, com ela, o surgimento da escola, se dá na transição do comunismo primitivo para o escravismo antigo, quando da ruptura do modo de produção comunal e o conseqüente surgimento da sociedade de classes. Ao longo de todo o período antigo e medieval, a escola permanecerá como forma restrita de educação somente ascendendo à condição de forma principal, dominante e generalizada de educação na época moderna.

Contudo, é preciso reconhecer a existência de uma certa literatura que faz coincidir, explicitamente, a origem da escola com o advento da moderna sociedade capitalista apagando, portanto, a referida distinção. Exemplo dessa literatura é o artigo de Guy Vincent, Bernard Lahire e Daniel Thin, "Sobre a história e a teoria da forma escolar" (Educação em Revista, n.33, 200 I , p.22-49), referido na nota I do capítulo 2, à página 5 I. Nesse artigo seus autores, para estabelecer o contraste entre as "formas sociais orais" e as "formas sociais escriturais-escolares", saltam diretamente da análise das sociedades "primitivas", de caráter mítico, para a sociedade moderna, representada pela "França urbana do fim do século XVII à primeira metade do século XIX" (p.25-26). Um outro exemplo pode ser encontrado no livro de Christian Baudelot e Roger Establet, L'école capitaliste en France (Paris, François Maspero, 197I), no qual se afirma que "o aparelho escolar, como produto histórico, é inseparável do modo de produção capitalista" (p.298).

Diferentemente dessas abordagens entendo que o processo de institucionalização da educação é correlato do processo de surgimento da sociedade de classes que, por sua vez, tem a ver com o processo de aprofundamento da divisão do trabalho. Assim, se nas sociedades primitivas, caracterizadas pelo modo coletivo de produção da existência humana, a educação consistia numa ação espontânea, não diferenciada das outras formas de ação desenvolvidas pelo homem, coincidindo inteiramente com o processo de trabaIho que era comum a todos os membros da comunidade, com a divisão dos homens em classes a educação também resulta dividida; diferencia-se, em conseqüência, a educação destinada à classe dominante daquela a que tem acesso a classe dominada. E é aí que se localiza a origem da escola. A palavra "escola", como se sabe, deriva do grego e significa, etimologicamente, o "lugar do ócio". A educação dos membros da classe que dispõe de ócio, de lazer, de tempo livre passa a se organizar na forma escolar, contrapondo-se à educação da maioria que continua a coincidir com o processo de trabalho.

Vê-se, pois, que já na origem da instituição educativa, ela recebeu o nome de escola. Essa origem da escola ligada à educação da classe dominante também é assinalada por Manacorda em História da educação (São Paulo, Cortez, 1989, p.14), quando aproxima os ensinamentos de Ptahhotep, no antigo Egito, que datam de 2.450 a.C., aos de Quintiliano, que viveu na antiga Roma entre os anos 30 e 100 de nossa era. Constatando que o "falar bem" é o conteúdo e o objetivo do ensinamento de Ptahhotep, Manacorda 
observa que não se trata, porém, do falar bem "em sentido estético-literário", mas da "oratória como arte política do comando", ou seja, nos termos de Quintiliano, "uma verdadeira institutio oratória, educação do orador ou do homem político". Acrescenta em seguida que entre o educador egípcio e o romano passaram-se mais de dois milênios e meio; "mais do que entre Quintiliano e nós"; e, não obstante as muitas diferenças entre as civilizações egípcia e romana, reconhece como legítima uma "continuidade de princípio na formaçã̃o das castas dirigentes nas sociedades antigas, e não somente naquelas". Retomando esse tema na conclusão de seu livro (p.356), Manacorda irá referir-se à "separação entre instrução e trabalho"; à distinção entre instrução intelectual "para os poucos" e "aprendizado do trabalho para os muitos"; e à definição da "instrução institucionalizada" como formação do governante, processo esse que logo se sedimenta e "se transforma numa instrução que cada vez mais define o seu lugar como uma 'escola', destinada à transmissão de uma cultura livresca codificada". E isso vale não apenas para as sociedades antigas, mas também para a sociedade moderna, caracterizando-se como um verdadeiro fenômeno de continuidade na descontinuidade.

Exige, também, certa cautela o conceito de "traços culturais" que teriam marcado a "formação histórica" brasileira, traços esses evidenciados pelos chamados "intérpretes do Brasil". Essa noção aproxima-se do conceito de "caráter nacional brasileiro", magistralmente desmontado por Dante Moreira Leite, já nos anos 50 do século XX, em sua tese de doutoramento denominada O caráter nacional brasileiro: descrição das características psicológicas do brasileiro através de ideologias e estereótipos, defendida na Faculdade de Filosofia da Universidade de São Paulo, em 1954 (Leite, D. M., O caráter nacional brasileiro: história de uma ideo- logia, $2^{\mathrm{a}}$ ed. revista, refundida e ampliada, São Paulo, Pioneira, 1969, 340 p.). Estimo que, com esse cuidado, a idéia da simultaneidade de diferentes tempos históricos condensados na prática escolar, inspirada em Lukács, que motivou a introdução do conceito de "traços culturais" próprios da formação social brasileira, resultará bem mais fértil.

Um outro ponto que suscita debate, diz respeito à expressão "cultura da escola". O que se quer, precisamente, entender com essa locução? Que conceito geral de cultura essa particularização estaria supondo? Quais os seus pressupostos teórico-filosóficos? É possível afirmar que a escola tenha uma cultura própria, distinta das culturas das demais instituições que convivem com ela em uma mesma formação social? Qual o grau de autonomia dessa "cultura escolar" em relação à cultura vigente na sociedade em que está inserida? Essa particularização da noção de cultura não estaria implicando a existência de uma multiplicidade de culturas no interior de uma mesma cultura? E o foco nas culturas particulares não estaria mascarando as características distintivas da cultura de uma sociedade considerada em seu conjunto, de determinada época histórica e, no limite, da própria humanidade?

À vista das indagações formuladas, ocorre-me lembrar a advertência de Álvaro Vieira Pinto no capítulo "Teoria da cultura", do livro Ciência e existência (Rio de Janeiro, Paz e Terra, 1969, p. I25). Considera ele que a realidade da cultura apresenta dupla face. Por uma, se materializa em "instrumentos, objetos manufaturados e produtos de uso corrente"; por outra, constitui "idéias abstratas, concepções da realidade, conhecimentos dos fenômenos e criações da imaginação artística", sendo ambas as faces correlacionadas pelas respectivas técnicas, 0 que faz com que o estudioso menos avisa- 
do se desoriente ao conceituar a cultura, "pois tem dificuldade em utilizar o método necessário para chegar à formulação racional do plano cultural em totalidade". Nessas condições, ainda segundo Vieira Pinto, a cultura aparece, "no estado atual, como um infinito complexo de conhecimentos científicos, de criações artísticas, de operações técnicas, de fabricação de objetos, máquinas, artefatos e mil outros produtos da inteligência humana". Daí, a dificuldade de se chegar a um conceito unificado de cultura que permita atingir uma compreensão coerente das múltiplas e diversificadas manifestações culturais. Para chegar a esse resultado Vieira Pinto entende ser necessário "assumir o ponto de vista genético, ligado a uma filosofia existencial e servido pela lógica dialética". Só por esse caminho será possível descobrir "a verdadeira realidade da cultura e seu fundamento no processo da produção".

Essa advertência parece-me pertinente, dado que João dos Reis e Celso Ferretti, colocando-se na perspectiva de Lukács, vinculam-se à mesma concepção filosófica de Álvaro Vieira Pinto, cuja matriz é a obra de Marx. Considero, pois, lícito alimentar a expectativa de que, partindo desse outro referencial teórico, os autores venham a trazer uma nova luz sobre o significado da expressão "cultura escolar", respondendo satisfatoriamente às questões formuladas. Mas não posso deixar, também, de reconhecer a validade da preocupação expressa por Newton Duarte no prefácio do livro, quando vê "sinais nítidos de influência pós-estruturalista e multiculturalista" na incorporação de autores como Beltrán Llavador, San Matín Alonso e Ball, para efeitos do estudo da cultura da escola. Com certa cumplicidade, Newton anota o contraargumento dos autores: a fertilidade teóricometodológica que resulta daquela incorporação. De minha parte, estou inteiramente disposto a admitir essa fertilidade sob a con- dição, porém, de que as análises incorporadas sejam desarticuladas do quadro teórico originário e rearticuladas no novo quadro. É isto que, para além desse livro, seus autores deverão efetivar na nova linha de pesquisa que propõem. Por ora, a impressão deixada pela leitura é que os autores se apropriaram das análises em torno do institucional, da organização e da cultura da escola e a elas aderiram como esclarecedoras da especificidade da escola, convertendo-as em elementos decisivos para o estudo da prática escolar. Advertidos da possível incompatibilidade entre esse tipo de análise e o referencial teórico lukacsiano por eles adotado, manifestaram-se em posição crítica mantendo, porém, a incorporação efetuada. $\bigcirc$ resultado foi que, a meu ver, todo o livro encontra-se atravessado por uma justaposição em que as apropriações de Lukács e Heller detêm-se em conceitos gerais relativos à "ontologia do ser social”, exigindo maior articulação com a prática escolar. Em contrapartida, nas referências à questão da escola intervêm sempre os conceitos de institucional, organização e cultura da escola que, como uma espécie de bordão, aparecem reiteradamente em diferentes momentos do texto. Considerando o propósito do livro, de "fazer uma primeira produção da categoria prática escolar com base na categoria 'prática social' tomada de Lukács", devemos aguardar o desenrolar das pesquisas para conhecer o conteúdo da categoria prática escolar que os autores pretendem produzir.

Os problemas apontados não diminuem, um milímetro sequer, a importância da obra. Ao contrário. Do ponto de vista do avanço do conhecimento, podemos dizer que a força de um livro e, portanto, a justificativa de sua publicação, se mede mais pelos problemas que suscita do que pelas respostas que proporciona. Portanto, as questões levantadas são um indicador do vi- 
goroso empreendimento abraçado pelos autores. E a generosa iniciativa de socializar suas preocupações e seu ponto de partida, que me deu o feliz ensejo de externar as questões trazidas pela leitura, com certeza será um forte estímulo a todos os demais leitores, provocando-os a tornar mais consistente a própria compreensão da prática escolar. O livro propicia, pois, um sadio debate sobre a especificidade do trabalho pedagógico escolar, com certeza o problema mais relevante da educação na atualidade. Sua leitura interessa, pois, a todos os professores que, tendo a escola como seu "habitat natural", não podem ficar indiferentes à exigência de elucidação da prática educativa que se desenvolve no interior da instituição que se tornou a forma principal, dominante e generalizada de educação.

Dermeval Saviani Professor Emérito da Universidade de Campinas dermevalsaviani@yahoo.com.br 